\title{
The coronin-like protein POD-1 is required for anterior-posterior axis formation and cellular architecture in the nematode Caenorhabditis elegans
}

\author{
Chad A. Rappleye, ${ }^{1}$ Alexander R. Paredez, ${ }^{1}$ Carol W. Smith, ${ }^{1}$ Kent L. McDonald, ${ }^{2}$ \\ and Raffi V. Aroian ${ }^{1,3}$ \\ ${ }^{1}$ Department of Biology, The University of California, San Diego, La Jolla, California 92093 USA; ${ }^{2}$ Electron Microscope Lab, \\ The University of California, Berkeley, Berkeley, California 94720 USA
}

Establishment of anterior-posterior (a-p) polarity in the Caenorhabditis elegans embryo depends on filamentous (F-) actin. Previously, we isolated an F-actin-binding protein that was enriched in the anterior cortex of the one-cell embryo and was hypothesized to link developmental polarity to the actin cytoskeleton. Here, we identify this protein, POD-1, as a new member of the coronin family of actin-binding proteins. We have generated a deletion within the pod-1 gene. Elimination of POD-1 from early embryos results in a loss of physical and molecular asymmetries along the a-p axis. For example, PAR-1 and PAR-3, which themselves are polarized and required for a-p polarity, are delocalized in pod-1 mutant embryos. However, unlike loss of PAR proteins, loss of POD-1 gives rise to the formation of abnormal cellular structures, namely large vesicles of endocytic origin, membrane protrusions, unstable cell divisions, a defective eggshell, and deposition of extracellular material. We conclude that, analogous to coronin, POD-1 plays an important role in intracellular trafficking and organizing specific aspects of the actin cytoskeleton. We propose models to explain how the role of POD-1 in basic cellular processes could be linked to the generation of polarity along the embryonic a-p axis.

[Key Words: Cell polarity; anterior-posterior axis; embryonic development; actin cytoskeleton; coronin; C. elegans]

Received May 27, 1999; revised version accepted September 17, 1999.

The polarization of cells to generate asymmetry is important in the development of organisms and individual cells. Asymmetry is central to mosaic development, in which sister cells take on different fates due to the differential localization of factors within a progenitor cell. Examples include establishment of mother/daughter differences in yeast, establishment of developmental axes in plants, establishment of neurogenic cell fates in Drosophila, and segregation of embryonic versus extra-embryonic cell fates in the mouse embryo. Polarization of cells and the asymmetric segregation of components within cells are also important in the development and function of many individual cell types, including epithelial and immune cells.

Although polarity is fundamental to many biological systems, our knowledge of the mechanisms that generate and maintain polarity is limited. One reason for this limited knowledge is that the mechanisms that generate polarity are linked to the physical architecture of the

${ }^{3}$ Corresponding author.

E-MAIL raroian@ucsd.edu; FAX (619) 822-2003. cell, that is, the cytoskeleton. In every example mentioned above, the actin cytoskeleton has been shown to play an important role in establishing or maintaining polarity (Gueth-Hallonet and Maro 1992; Fowler and Quatrano 1995; Drubin and Nelson 1996; Broadus and Doe 1997; Takizawa et al. 1997; Penninger and Crabtree 1999; Winckler et al. 1999). Yet because the cytoskeleton is integral to many functions within the cell, it has been difficult to study its role in specific processes such as the generation of asymmetry.

The one-cell Caenorhabditis elegans embryo has become important for studying how developmental asymmetry is established (for review, see Bowerman 1998). The first cell division of the zygote is asymmetric, giving rise to a large anterior daughter, $\mathrm{AB}$, and a smaller posterior daughter, $\mathrm{P}_{1}$. These two cells have different cellintrinsic fates: $\mathrm{AB}$ makes much of the neuroectoderm and $\mathrm{P}_{1}$ makes most of the mesoderm, endoderm, and germ line. Several genes important for establishing physical and developmental differences between $\mathrm{AB}$ and $\mathrm{P}_{1}$ have been identified and are themselves asymmetrically localized during the first cell cycle in the one-cell 
embryo. These genes are called the par genes for partitioning defective. Homologs of some par genes appear to be important for the polarity of mammalian epithelial cells, suggesting elements of the pathway are conserved from nematodes to mammals (Boehm et al. 1997; Izumi et al. 1998).

Pharmacological disruption of the actin cytoskeleton indicates that, like the PAR proteins, actin plays a central role in polarizing the one-cell C. elegans embryo (Hill and Strome 1988). To begin to understand the role of filamentous actin (F-actin) in generating polarity and to get at the mechanism by which the polarity is generated, we isolated F-actin-binding proteins from C. elegans oocytes (Aroian et al. 1997). One of these, CABP11, is polarized along the anterior-posterior (a-p) axis of the one-cell embryo, suggesting it might provide a link between F-actin and the generation of polarity.

Here we identify the gene that encodes CABP11 and study its loss-of-function phenotypes and cellular localization in detail. This gene, named pod-1 for polarityosmotic defective 1 , encodes a protein with novel homology to the coronin family of F-actin-binding proteins. Coronin, a WD-repeat-containing protein, is important for intracellular trafficking (endocytosis, phagocytosis) and cell motility in Dictyostelium and may play similar roles in mammalian cells (De Hostos et al. 1993; Maniak et al. 1995; Grogan et al. 1997; Hacker et al. 1997; David et al. 1998). Elimination of POD-1 protein from embryos results in a par phenotype and loss of a-p polarity. The asymmetric localization of POD-1, like the localization of some PAR proteins, is cell cycle dependent in the early embryo. However, unlike the loss of other polarity or PAR proteins characterized to date, loss of pod-1 leads to dramatic and specific alterations in the internal and external structure of embryonic cells, including the formation of abnormal endocytic vesicles, membrane protrusions, abnormal eggshells, and the deposition of extracellular plaque material. Many of these defects are analogous to those in the Dictyostelium coronin mutant and suggest that a primary role of pod-1 is in intracellular trafficking and cytoskeletal organization. Our study of pod-1 demonstrates that the one-cell embryo is suited not only for studying proteins with specialized roles in development but also for understanding how developmental processes are linked to cellular architecture. On the basis of the effects of pod-1 on both polarity and architecture, we propose models for how a-p polarity is generated in the early embryo.

\section{Results}

pod-1 encodes new member of the coronin family of actin-binding proteins

The enrichment of CABP11 at the anterior cortex in the one-cell embryo suggested that it was a component of the actin cytoskeleton involved in generating polarity (Aroian et al. 1997). To study CABP11 in more detail, we cloned the gene that encodes this protein. A complete
cDNA was isolated with a single open reading frame (ORF). Subsequently, the C. elegans genome project sequenced this region of the genome and predicted an ORF (Y76A2B.1) with the same intron/exon structure as our cDNA sequence (Fig. 1A). This gene was name pod-1 based on its loss-of-function phenotypes (see below). In keeping with C. elegans nomenclature, CABP11 protein is renamed POD-1.

The pod-1 gene encodes a protein of 1057 amino acids with significant identity to the actin-binding protein coronin. POD-1 contains two nearly complete, degenerate copies of the coronin protein. Amino acids 7-386 and 554-942 of POD-1 are each $27 \%-28 \%$ identical to the first 386 amino acids of Dictyostelium and human coronins (Fig. 1B; the entire Dictyostelium coronin is 445 amino acids long). In addition, the two POD-1 coronin domains are $27 \%$ identical to each other. However, POD-1 is not the closest homolog to coronin in the $C$. elegans genome. C. elegans ORF R01H10.3 is $40 \%$ identical to Dictyostelium coronin, contains a single coronin domain, and is more similar in gene structure to other members of the coronin family (Goode et al. 1999). Neither the 167 amino acids between the two coronin domains of POD-1 nor the 115 amino acids at the carboxyl terminus of POD-1 show significant similarities to other known proteins. POD-1 contains four WD repeats within the two coronin domains and one proline-rich region between the coronin domains (Fig. 1A). POD-1 lacks the $\alpha$-helical coiled-coil domain found at the carboxyl terminus of other coronins. Nonetheless, given that this domain is thought to be involved in coronin dimerization (Goode et al. 1999), it is possible that POD-1 has circumvented the need for a coiled-coil domain by duplicating coronin in the same protein.

pod-1 plays a specialized role in embryonic development

To determine what role POD-1 plays in embryonic development, we generated a deletion allele of pod-1 to study its loss-of-function phenotype. This allele, called pod-1(ye11), contains a 1451-base deletion within the pod-1 gene that when translated results in a frameshift at amino acid residue 304 (Fig. 1B) followed by 13 additional missense residues and a stop codon. This allele is probably a null based on the following data. First, embryos derived from hermaphrodites of the genotype pod1(ye11)/eDf2 (where eDf2 is a large chromosomal deficiency that spans the pod-1 locus) are not more severe in phenotype than embryos derived from homozygous pod1(ye11) hermaphrodites. Second, attempts to further reduce POD-1 protein levels by injection of doublestranded RNA (Fire et al. 1998) into the pod-1(ye11) homozygous mothers did not increase the severity of mutant embryonic phenotypes.

Loss of pod-1 leads to strict maternal effect embryonic lethality, suggesting pod-1 plays a specialized role in embryonic development. unc-32(e189) pod-1(ye11)/unc$32(+)$ pod $-1|+|$ hermaphrodites segregate $25 \%$ Unc Pod 
Rappleye et al.

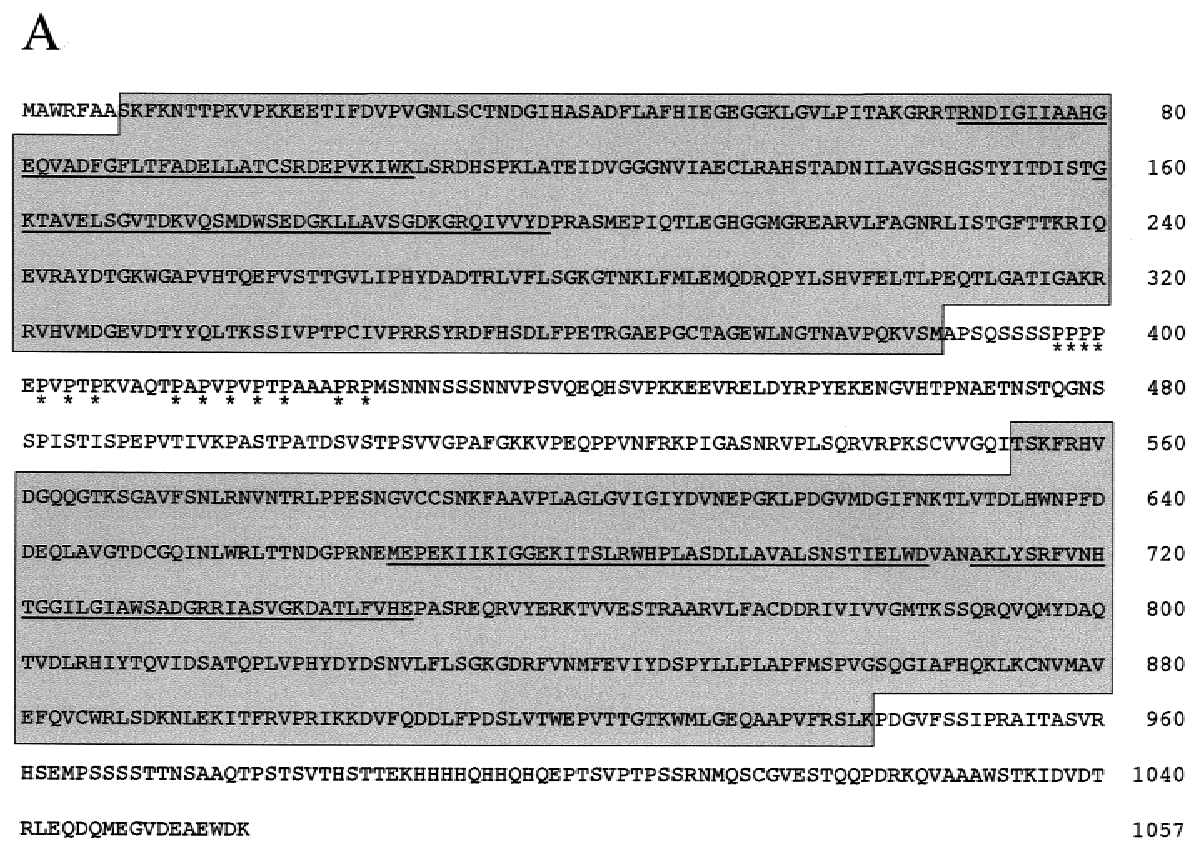

B

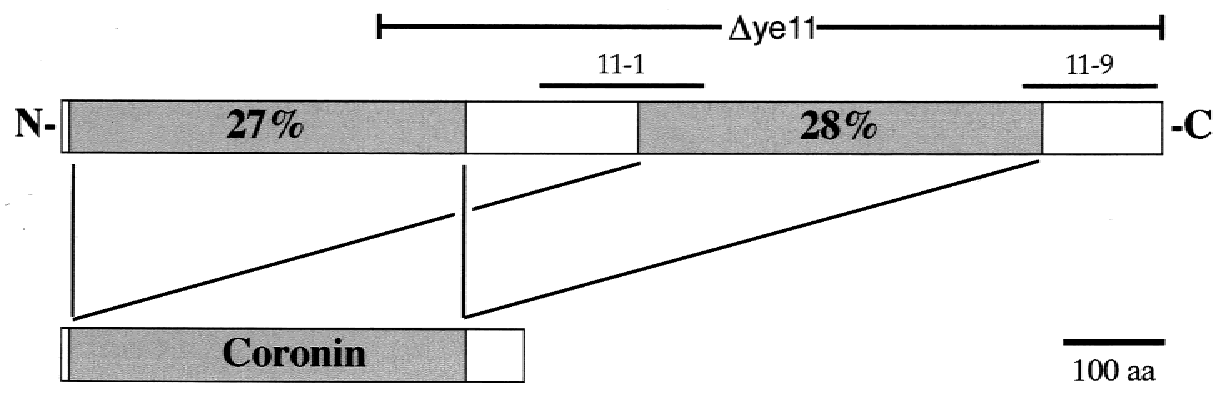

Figure 1. The sequence of POD-1 contains two regions with significant similarity to coronin. (A) Predicted amino acid sequence of POD-1. The two separate regions showing sequence similarity to coronin are shaded. Predicted WD-motifs are underlined and the proline-rich region is indicated by asterisks. $(B)$ Schematic representation of POD-1 showing the two regions of coronin homology and the respective sequence identity shared with Dictyostelium coronin. Lines above the POD-1 protein indicate residues removed by the deletion allele ye11 and the location of the POD-1 polypeptides used to generate the 11-1 and 11-9 antibodies.

progeny, indicating zygotic pod-1 function is dispensable for viability. Conversely, all embryos derived from mothers homozygous for pod-1(ye11) arrest before hatching (Table 1). Thus, maternal pod-1 is essential for embryonic viability. To further test the maternal pod-1 requirement, wild-type males were mated to pod-1(ye11) hermaphrodites. No viable progeny $(0 / 334)$ were produced in these crosses, confirming that pod-1 function is strictly dependent on the maternal contribution. Embryos derived from homozygous pod-1(ye11) mothers are hereafter referred to as pod-1 mutant embryos.

POD-1 is required for a-p polarity in the early embryo

We then analyzed pod-1 mutant embryos in detail to determine whether pod-1 plays a role in a-p axis formation. Genes required for embryonic a-p polarity in $C$. elegans can be identified on the basis of their effects on early cleavage patterns and segregation of germ-line $(\mathrm{P})$ granules to the germ-line lineage. Loss-of-function in polarity genes (e.g., par-1 or par-3) eliminates differences in the behavior of embryonic cells along the a-p axis. The first cleavage in these mutants is often symmetric, resulting in two equal-sized daughter cells. Furthermore,

Table 1. Loss of pod-1 function leads to defects in embryogenesis

\begin{tabular}{lcc}
\hline & \multicolumn{2}{c}{ Fraction of embryos } \\
\cline { 2 - 3 } $\begin{array}{l}\text { Relevant } \\
\text { genotype }\end{array}$ & inviable & $\begin{array}{c}\text { symmetric } \\
\text { first cleavage }\end{array}$ \\
\hline pod-1 $(+)$ & $0.00(\mathrm{n}=311)$ & $0.00(\mathrm{n}=20)$ \\
pod-1(ye11) & $1.00(\mathrm{n}=294)$ & $0.54(\mathrm{n}=26)$ \\
pod-1(RNAi) & $1.00(\mathrm{n}=286)$ & $0.08(\mathrm{n}=197)$ \\
coronin(RNAi) & $<0.01(\mathrm{n}=312)$ & $0.00(\mathrm{n}=18)$ \\
\hline
\end{tabular}


the two equal-sized daughters in the mutants often divide synchronously and in parallel orientations. These lineage patterns of the par mutants are unlike those of wild type in which the first division is asymmetric and the second divisions are asynchronous and orthogonal (Fig. 2A). P granules that segregate with the germ-line lineage are also mislocalized in the par mutants. In wildtype embryos, $\mathrm{P}$ granules are partitioned to the posterior of all one-cell embryos by metaphase of the first cell cycle so that they are inherited only by the germ-line precursor $\mathrm{P}_{1}$ (Table 2 and Fig. 2C). In par mutants, the localization of $\mathrm{P}$ granules is often abnormal (Kemphues et al. 1988).
The pod-1 gene is required for all these aspects of a-p polarity. More than half the time, one-cell pod-1 mutant embryos divide symmetrically, giving rise to two daughter blastomeres of equal size (Table 1 and Fig. 2B). Like the other polarity mutants listed above, these daughter cells then divide synchronously and in parallel orientation. In the pod-1 mutant, the orientations of these divisions are both dorsal-ventral, similar to that found in par-2 and nmy-2 mutants. Thus, one- and two-cell embryos lacking pod-1 often fail to show the normal physical differences associated with the a-p axis.

POD-1 is also required for proper partitioning of $\mathrm{P}$ granules. In one-cell pod-1 mutant embryos, $\mathrm{P}$ granules

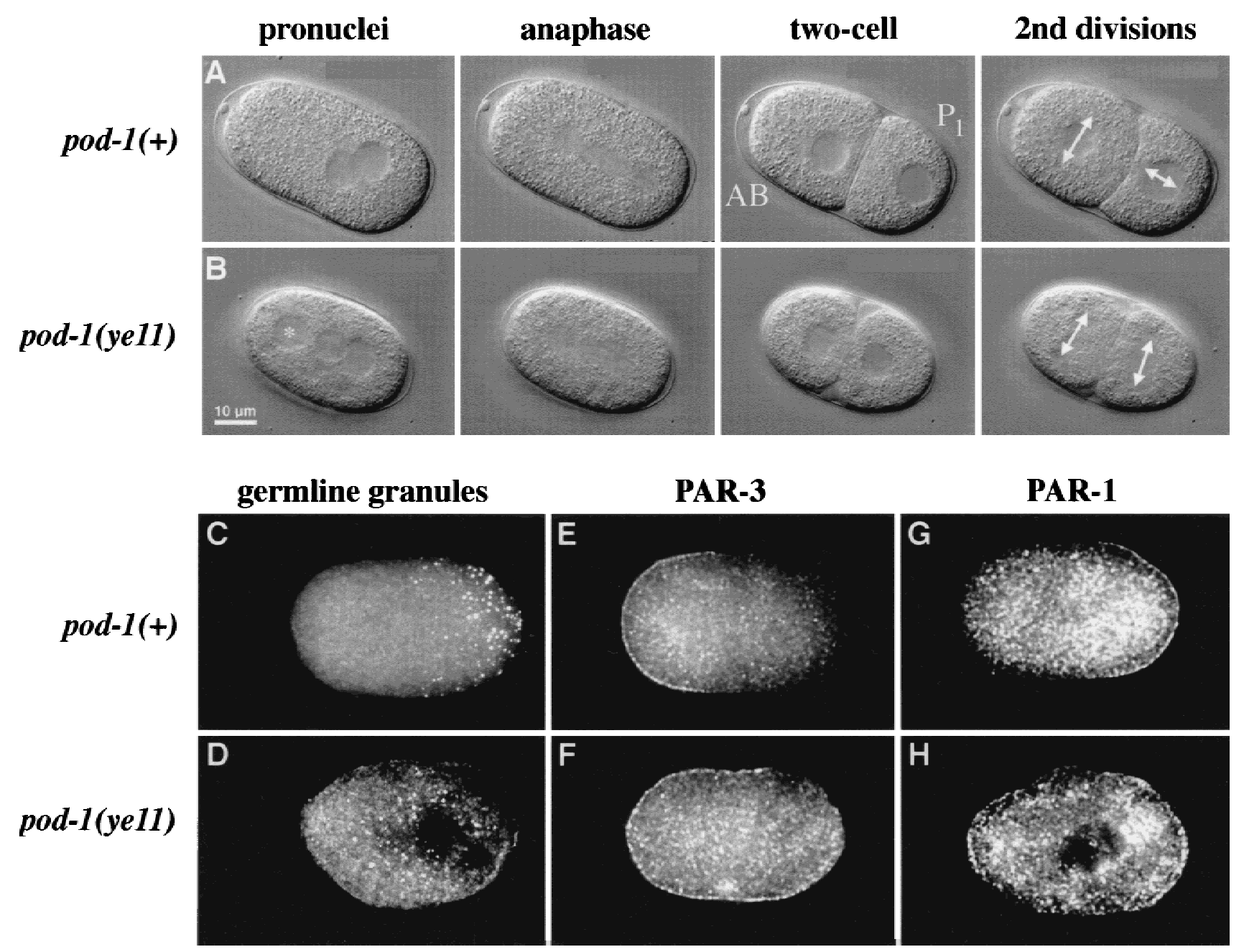

Figure 2. Loss of pod-1 function leads to defects in physical and molecular markers of a-p polarity. All embryos are oriented with left being anterior. $(A, B)$ DIC images. $(C-H)$ Immunofluorescence images. $(A)$ Wild-type one-cell embryo dividing asymmetrically into AB and $\mathrm{P}_{1}$. (Right) Orthogonal orientations of the next round of divisions are indicated by arrows. These divisions will also occur asynchronously with $\mathrm{AB}$ dividing before $\mathrm{P}_{1}$. (B) A pod-1(ye11) one-cell embryo dividing symmetrically into equivalently sized blastomeres. The next round of divisions occurs synchronously and in parallel orientations (arrows, right). pod-1(ye11) mutant embryos are slightly smaller (see text) and also fail to extrude polar bodies, which appear as an additional pronucleus (asterisk). (C-H) One-cell embryos between pronuclear meeting and anaphase showing the distribution of P granules, PAR-3, and PAR-1. (C) In pod-1(+) embryos, P granules are segregated to the posterior cytoplasm. (D) pod-1(ye11) mutant embryos fail to properly segregate P granules. (E) PAR-3 is restricted to the anterior cortex of pod-1(+) embryos. $(F)$ Loss of pod-1 causes delocalization of PAR-3 to both the anterior and posterior cortices. $(G)$ Cortical PAR-1 is restricted to the posterior of pod-1(+) embryos. $(H)$ Loss of pod-1 causes delocalization of PAR-1 to both the anterior and posterior cortices. 
Rappleye et al.

Table 2. Distribution of molecular markers of asymmetry in one-cell pod-1(+) and pod-1(ye11) embryos ${ }^{a}$

\begin{tabular}{|c|c|c|c|c|c|c|c|c|}
\hline \multirow[b]{2}{*}{$\begin{array}{l}\text { Relevant } \\
\text { genotype }\end{array}$} & \multicolumn{2}{|c|}{$\begin{array}{l}\text { Germ-line granule } \\
\text { segregation }^{\mathrm{b}}\end{array}$} & \multicolumn{3}{|c|}{$\begin{array}{c}\text { Cortical } \\
\text { PAR-3 localization }\end{array}$} & \multicolumn{3}{|c|}{$\begin{array}{c}\text { Cortical } \\
\text { PAR-1 localization }^{\mathrm{f}}\end{array}$} \\
\hline & $\begin{array}{c}\text { early } \\
\text { cell cycle }\end{array}$ & $\begin{array}{c}\text { late } \\
\text { cell cycle }\end{array}$ & $\begin{array}{c}\text { anterior } \\
\text { only }\end{array}$ & $\begin{array}{c}\text { anteriorly } \\
\text { enriched }\end{array}$ & symmetric & $\begin{array}{l}\text { posterior } \\
\text { only }\end{array}$ & $\begin{array}{c}\text { posteriorly } \\
\text { enriched }\end{array}$ & symmetric \\
\hline pod-1 $1+1$ & 1.00 & 1.00 & 0.89 & 0.11 & 0.00 & 0.96 & 0.00 & 0.04 \\
\hline pod-1(ye11) & 0.04 & 0.43 & 0.00 & 0.26 & 0.71 & 0.00 & 0.34 & 0.66 \\
\hline
\end{tabular}

${ }^{a}$ Numbers represent fraction of total embryos examined.

${ }^{\text {b }}$ Segregation of germline granules to posterior $1 / 2$ of the one-cell embryo.

'Pronuclear meeting to metaphase. $\mathrm{n}=20$ pod-1 $(+)$ and $\mathrm{n}=25$ pod-1(ye11).

${ }^{\mathrm{d}}$ Anaphase to telophase. $\mathrm{n}=15$ pod-1 $(+)$ and $\mathrm{n}=21$ pod-1 (ye11).

${ }^{\text {e}}$ Pronuclear meeting through anaphase. $\mathrm{n}=18 \operatorname{pod}-1(+)$ and $\mathrm{n}=31$ pod-1(ye11). anterior only $=$ restricted to anterior $2 / 3$ of cortex; anteriorly enriched $=$ found in anterior and posterior cortex but enriched at one pole; symmetric $=$ equivalent levels at anterior and posterior ends.

${ }^{\mathrm{f}}$ Pronuclear meeting through anaphase. $\mathrm{n}=27$ pod-1 $(+)$ and $\mathrm{n}=35$ pod-1(ye11). posterior only $=$ restricted to posterior $1 / 2$ of cortex; posteriorly enriched $=$ found in anterior and posterior cortex but enriched at one pole; symmetric $=$ equivalent levels at anterior and posterior ends.

are rarely segregated to the posterior by metaphase (Table 2 and Fig. 2D). By telophase, P granules are found localized in the posterior in $43 \%$ of one-cell pod-1(ye11) embryos (Table 2). Thus, there are two different defects in $\mathrm{P}$ granule segregation in the pod-1(ye11) mutant. In most one-cell mutant embryos, $\mathrm{P}$ granules fail to segregate. In the others, segregation occurs, but is temporally delayed.

Because pod-1 affects the movement of P granules, we wanted to determine whether pod-1 affects the asymmetric flows that are thought to move the $\mathrm{P}$ granules to the posterior (Hird and White 1993; Hird et al. 1996). At the time of anterior membrane ruffling early in the first cell cycle, anteriorly directed cortical and posteriorly directed cytoplasmic flows can be discerned in wildtype embryos by following cytoplasmic granule movements in time-lapse video recordings (Hird and White 1993). We recorded on videotape four pod-1 mutant embryonic lineages from this very early stage of development. In all four embryos, flows were absent, similar to what has been reported in the par-3 mutant (Kirby et al. 1990).

pod-1(ye11) mutant phenotypes have also been confirmed using double-stranded RNA-mediated interference (called RNAi; Rocheleau et al. 1997) to eliminate pod-1 function from embryos. Embryos depleted of POD-1 this way are not viable (Table 1) and show polarity and physical defects (described below). However, the frequency of most of these defects (viability and osmotic sensitivity are exceptions) is less than the frequency seen with the ye11 deletion mutant (Table 1). Therefore, pod-1 RNAi seems to produce a reduction, but not a loss, of pod-1 function. We have also used RNAi to eliminate R01H10.3, the other C. elegans coronin-related protein, from embryos. These embryos all hatch (Table 1). Furthermore, injection of R01H10.3 double-stranded RNA into ye11 hermaphrodites does not increase the severity of pod-1 phenotypes in the progeny (not shown). These data suggest that POD-1 is the only coronin-like protein required for embryonic development.
POD-1 is localized asymmetrically in early embryonic cells in a cell cycle dependent-manner

Many PAR proteins are localized asymmetrically in the germ-line precursor cells $\mathrm{P}_{0}, \mathrm{P}_{1}$, and $\mathrm{P}_{2}$. Furthermore, this asymmetric localization is cell cycle dependent such that the extent of asymmetry varies during the cell cycle (Etemad-Moghadam et al. 1995; Guo and Kemphues 1995; Boyd et al. 1996). These data suggest that the processes that generate polarity are dynamic. Because POD-1 is localized asymmetrically in $\mathrm{P}_{0}$ and $\mathrm{P}_{1}$ (Aroian et al. 1997) and as POD-1 is phenotypically a par mutant, we set out to determine whether POD-1 localization is also regulated by the cell cycle.

Like PAR protein localizations, POD-1 localization in $\mathrm{P}$ cells is cell cycle dependent. In the earliest one-cell embryos before pronuclear meeting $\left(\mathrm{P}_{0}\right)$, cortical POD-1 is either anteriorly enriched (12/24 embryos; Fig. 3A), posteriorly enriched (5/24 embryos), or uniformly localized (7/24 embryos). From pronuclear meeting to metaphase, cortical POD-1 is almost always anteriorly enriched (30/39 embryos; Fig. 3B). At anaphase, POD-1 begins to transition from asymmetric to symmetric localization, such that by telophase cortical POD-1 can be found at equivalent levels in the anterior and posterior cortices (10/11 embryos; Fig. 3C). In addition to cell cortices, POD-1 antibodies stain punctate cytoplasmic structures. Although POD-1 and PAR-3 are both enriched in the anterior, their behavior in the posterior is different. POD-1 can be found in the posterior-most cortex, albeit at lower levels than the anterior (Fig. 3A). This localization is unlike PAR-3, which is sharply restricted to the anterior (see Fig. 2E; Etemad-Moghadam et al. 1995). The localization of POD-1 in the germ-line precursors of the two-cell and four-cell embryo is also cell cycle dependent such that early in the cell cycle, POD-1 is not asymmetric along the a-p axis, but becomes anteriorly enriched leading up to metaphase (Fig. 3D-F).

To confirm that the localization patterns described are specific to POD-1, we stained pod-1(ye11) mutant em- 


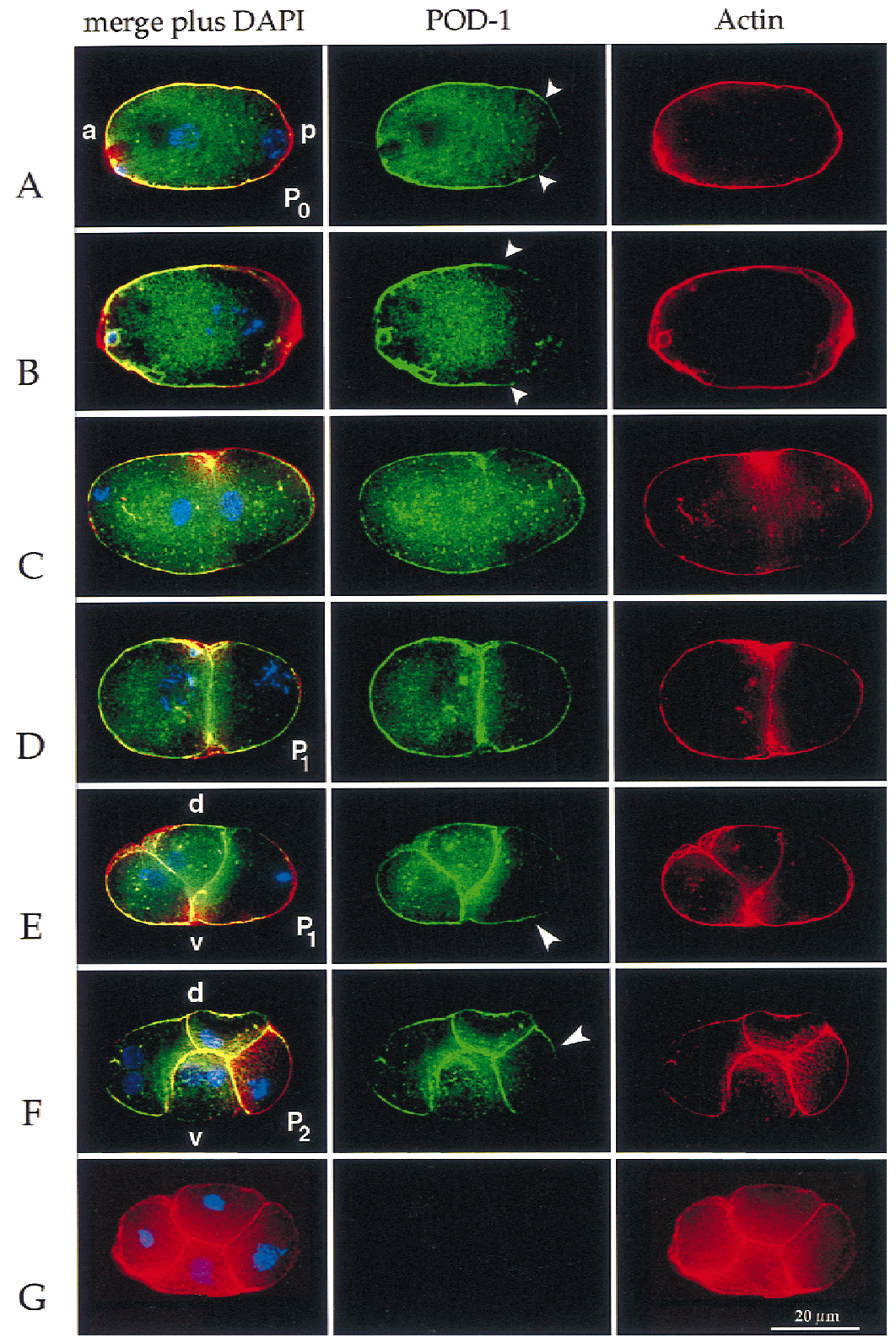

Figure 3. POD-1 is localized asymmetrically in germ-line blastomeres in a cell cycle-dependent fashion. Immunofluorescence images of POD-1 (green), actin (red), and DNA (blue) staining in early C. elegans embryos. All embryos are oriented with anterior to the left. All embryos are wild type except for $G$. $(A)$ One-cell embryo in pronuclear migration showing asymmetric POD-1 (extent indicated by arrowheads). (B) One-cell embryo in prometaphase showing asymmetric POD-1 (extent indicated by arrowheads). The difference in POD-1 staining between $A$ and $B$ is indicative of various extents of POD-1 asymmetry. (C) One-cell embryo in telophase. POD-1 stains equally the anterior and posterior cortex and localizes to the cleavage furrow. $(D)$ Early two-cell embryo with $\mathrm{P}_{1}$ in early prometaphase. Cortical POD-1 is present in the posterior of $\mathrm{P}_{1}$. (E) Two-cell embryo with $\mathrm{P}_{1}$ in metaphase. POD-1 staining is depleted from the posterior and is enriched at the anterior-ventral cortex of $\mathrm{P}_{1}$ (arrowhead). (F) A four-cell embryo with $\mathrm{P}_{2}$ in metaphase. POD-1 is enriched on the anteriordorsal side (arrowhead). (G) A pod-1(ye11) fourcell embryo. There is no detectable POD-1 staining in the mutant, but cortical actin is still present. (a) Anterior; (p) posterior; (d) dorsal; (v) ventral.

bryos with both of our POD-1 antibodies. All cortical and cytoplasmic POD-1 staining is eliminated in the mutant embryos (Fig. 3G).

\section{POD-1 and PAR proteins are mutually dependent} for polarized localization

The similarity of pod-1 and par mutant polarity phenotypes and cell cycle-dependent localizations suggested that POD-1 and the PAR proteins function in the same pathways. To examine the relationship of POD-1 to the PAR proteins further, we determined whether PAR protein polarization requires POD- 1 and vice versa. In wildtype one-cell embryos, PAR-3 protein is almost completely restricted to the anterior cortex, whereas PAR-1 protein is restricted to the posterior cortex (Fig. 2E, G and
Table 2; Etemad-Moghadam et al. 1995; Guo and Kemphues 1995).

pod-1 is required for polarization of PAR-3 at the anterior and PAR-1 at the posterior end of the embryo. In pod-1(ye11) mutant embryos, PAR-3 is no longer restricted to the anterior cortex (Fig. 2F and Table 2). In most, there is no a-p asymmetry of PAR-3 staining around the cortex, but anterior asymmetry persists in some mutant embryos. Similarly, in pod-1(ye11) mutant embryos, PAR-1 is no longer restricted to the posterior cortex. In the majority of cases, there is no a-p asymmetry in PAR-1 staining around the cortex (Fig. $2 \mathrm{H})$, but posterior enrichment persists in some embryos (Table 2). The percent of pod-1 mutant embryos showing loss of PAR-1 and PAR-3 polarization is greater than the percent of embryos that divide symmetrically. This comparison suggests that even in pod-1 mutant embryos that divide 
Rappleye et al.

asymmetrically, aspects of polarity are nonetheless perturbed.

We reciprocally tested whether par-1 and par-3 are required for POD-1 localization. In par-1 mutant embryos, there is still substantial POD-1 asymmetry as most embryos between pronuclear meeting and metaphase show anterior POD-1 enrichment (20/21; not shown). In par-3 mutant embryos, POD-1 asymmetry is disrupted as 0 of 23 embryos between pronuclear meeting and metaphase showed anterior enrichment of POD-1. Previously, we reported that POD-1 was absent in some par-3 mutant embryos (Aroian et al. 1997). Our current results probably reflect an enhanced sensitivity of the new POD-1 antibodies. We also examined POD-1 localization in the par-2 and par-4 mutants and found that 9 of 23 and 15 of 23 embryos, respectively, showed anterior enrichment. Thus, par-3 and, in most cases, par-2 are required for POD-1 asymmetry; par-1, and in most cases, par-4, are not required.

Loss of pod-1 results in defects in the structure of embryonic cells

The above analyses demonstrate that pod-1, like the par genes, is required for a-p embryonic polarity. However, by observing live pod-1 mutant embryos divide, it is readily apparent that pod-1 is uniquely different from other known polarity genes. That is because in addition to the polarity defects characterized above, loss of pod-1 also results in striking structural defects. These defects have not been previously characterized in C. elegans embryos.

Embryos lacking pod-1 often contain large, circular, granule-free zones (Fig. 4A). Such zones are not observed in wild type. These structures do not stain with the DNA stain DAPI and do not undergo nuclear envelope breakdown during mitotic stages, indicating they are not nuclei. Because coronin plays a major role in endocytosis in Dictyostelium (Hacker et al. 1997; Rauchenberger et al. 1997), we speculated these structures might be endocytic in origin. To test this hypothesis, wild-type and mutant embryos were stained with the fluorescent dye FM 4-64. FM 4-64 labels the plasma membrane and endocytic pathway upon internalization (Vida and Emr 1995). In laser-permeabilized wild-type embryos or in isolated blastomeres, FM 4-64 rapidly stains the plasma membrane as well as punctate structures in the cell (data not shown), which are probably endocytic in origin. These data indicate that wild-type C. elegans embryos are actively engaged in endocytosis, a fact not previously
Figure 4. Loss of pod-1 function leads to the formation of abnormal cellular structures. $(A, C, E-J)$ DIC images. $(B, D)$ Fluorescent images showing FM 4-64 staining. Anterior is oriented to the left in each image. (A) Dividing one-cell pod-1(ye11) embryo containing a large circular granule-free zone (arrow). $(B)$ The same embryo as in $A$. The circle stains with FM 4-64, indicating it is endocytic in origin (arrow). (C) One-cell pod-1(ye11) late anaphase embryo with a large hyaline protrusion at the posterior (arrowhead). (D) The same embryo as in $C$. The hyaline protrusion is contained within the plasma membrane but does not form an intracellular compartment (arrowhead). $(E-G)$ Time-lapse series of images of a pod1(ye11) mutant embryo with cell division defects at the one- to two-cell stage. (E) The first cleavage furrow has formed and appears to be complete. $(F)$ Within a few minutes, the division vanishes leading to the formation of a multinucleated cell. $(G)$ Subsequent division attempts lead to additional cleavage furrows. $(H-J)$ Osmotic sensitivity of pod-1(ye11) mutant embryos. (H) In 100 $\mathrm{mm} \mathrm{KCl,} \mathrm{pod-1(ye11)} \mathrm{mutant} \mathrm{embryonic} \mathrm{cells}$ swell. (I) In $150 \mathrm{~mm} \mathrm{KCl}$, pod-1(ye11) mutant embryonic cells have morphology similar to wild type. (J) In $250 \mathrm{~mm} \mathrm{KCl}$, pod-1(ye11) mutant embryos shrink and become highly refractile.
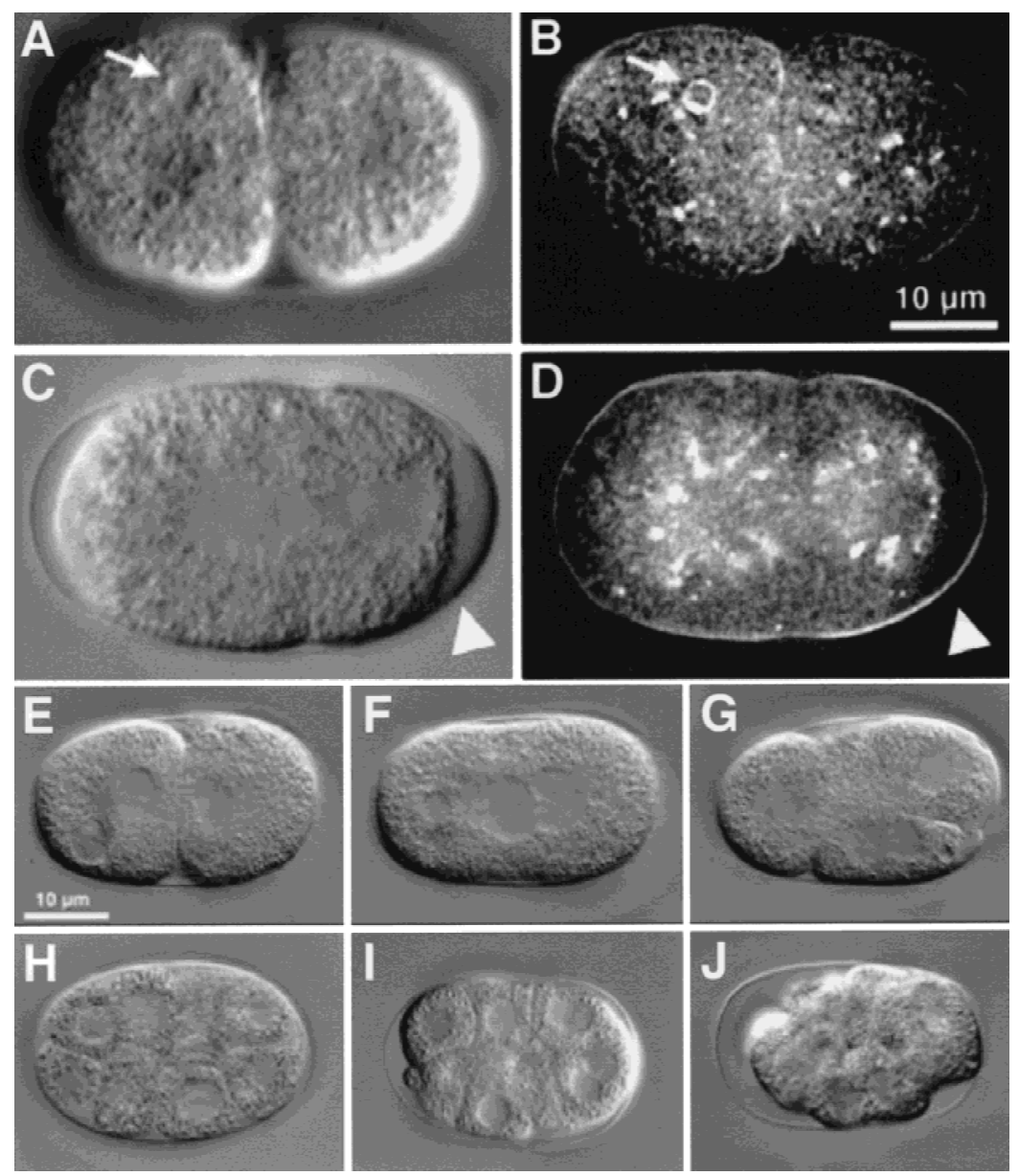
documented. In pod-1(ye11) mutant embryos, which are readily permeable to the dye without laser treatment (see below), FM 4-64 also stains the plasma membrane and punctate structures inside embryonic cells, indicating that endocytosis is occurring in the mutant (Fig. 4B). In addition, the large, abnormal circular structures stain with the dye, suggesting they are endocytic in origin (Fig. 4B). Their large size suggests there is some abnormality in the endocytic pathway.

Embryonic cells lacking pod-1 sometimes protrude transient granule-free (hyaline) zones at the cell periphery, a phenotype seen in Dictyostelium coronin mutants (Gerisch et al. 1995). These protrusions reproducibly form at the posterior-most end of asymmetrically dividing one-cell embryos in anaphase (Fig. 4C,D), as well as other peripheral locations. We are uncertain of the cause of these protrusions, although in Dictyostelium they are thought to arise from an abnormal polymerization of actin.

Lack of pod-1 also results in a variably penetrant cell division defect. Cytokinesis proceeds normally in all pod-1(ye11) one-cell embryos and progresses to apparent completion. However, in a few embryos (19\%), the membrane between the cells vanishes after several minutes (Fig. 4E-G). It does not regress from a single point, as would be expected for a defect in late stages of cytokinesis. Rather, it disappears over the length of the cellcell boundary. In embryos that do not show a cell division defect at the one- to two-cell stage, many $(47 \%)$ show a defect in cell division at the two- to four-cell stage. This defect in division can occur in either lineage $\left(\mathrm{AB}\right.$ or $\left.\mathrm{P}_{1}\right)$, but always involves sibling blastomeres. Embryos lacking pod-1 function also fail to extrude polar bodies after completion of meiosis. The polar body in pod-1 mutant embryos appears as an additional nuclear structure that associates with the maternal pronucleus (Fig. 2B), stains with DAPI, and undergoes nuclear envelope breakdown.

Because POD-1 likely binds actin directly, based on its purification and homology to coronin, and as coronin is hypothesized to influence the state of actin in cells (Goode et al. 1999), we investigated whether loss of pod-1 function leads to defects in actin organization. pod-1 mutant embryos generated by RNAi or from the ye11 allele were fixed and stained with actin antibody. In either case, loss of pod-1 does not lead to overt perturbations in the intensity and organization of cortical actin relative to control embryos (see Fig. 3G).

Although pod-1 mutant embryos display dramatic abnormalities in the physical structure of embryonic cells, loss of POD-1 protein does not lead to general cell failure. pod-1(ye11) mutant embryos still progress through the first cell cycle with normal timing (data not shown). Furthermore, pod-1(ye11) is a strict maternal effect lethal, demonstrating that pod-1 is not generally required for all developmental stages or in dividing cells. We have noticed that embryos produced by pod-1(ye11) mothers are slightly smaller $(81 \pm 8 \%)$ than control embryos.

The loss of a-p polarity described above cannot be attributed solely to some of the physical defects described in this section. For example, other mutants that fail to extrude polar bodies, have cytokinesis defects, or that produce smaller embryos still give rise to asymmetric cleavage and proper segregation of $\mathrm{P}$ granules at the onecell stage (S. Basham and L. Rose, pers. comm.; Denich et al. 1984; Swan et al. 1998).

Loss of pod-1 results in osmotic sensitivity and permeability to dyes

All pod-1 mutant embryos produced either by the ye11 allele or by double-stranded RNA are sensitive to their osmotic environment. Wild-type embryos proceed through early development normally in salt concentrations ranging from 0 to $500 \mathrm{~mm} \mathrm{KCl} \mathrm{(data} \mathrm{not} \mathrm{shown).} \mathrm{When} \mathrm{un-}$ treated pod-1(ye11) embryos are placed in isotonic media, they progress with normal timings through the first cell cycle and, aside from the polarity and physical defects mentioned above, exhibit normal cellular morphology (Fig. 4I). However, when placed in slightly hypotonic or hypertonic media, pod-1 mutant embryos swell or shrink within the eggshell and virtually cease progression through the cell cycle (Fig. $4 \mathrm{H}, \mathrm{J})$.

Osmotic sensitivity in the pod-1 mutant is unrelated to the other defects detailed above as all pod-1 mutant embryos are osmotically sensitive independent of whether their a-p axis forms normally or whether they display cell division defects. Conversely, pod-1 polarity and physical defects cannot be explained by osmotic imbalances. pod-1(ye11) mutant embryos that are allowed to develop either in utero (an osmotically ideal environment) or in blastomere media (which permits development of isolated embryonic cells) display the full range of polarity and physical defects. Furthermore, we have lineaged other previously identified osmotically sensitive mutants in our buffers (emb-14 and emb-20). These mutants do not show symmetric cleavages and loss of a-p polarity. Thus, the fact that the embryos are osmotically sensitive is not sufficient to account for the loss of polarity in the pod-1 mutant.

We discovered that, in addition to their inability to protect themselves against deleterious changes in their salt environment, pod-1 mutant embryos are also permeable to fluorescent dyes. Wild-type embryos with intact eggshells are impermeable to DAPI and FM 4-64. However, untreated pod-1(ye11) embryos are readily permeable to both dyes, which enter the cells and rapidly stain DNA and membrane structures respectively (Table 3; Fig. 4B,D).

This sensitivity to external salt concentration and permeability to dyes is not found with other published polarity mutants. We tested embryos mutant for par-1, par2, par-3, par-4, par-5, and par-6 and found that they are neither sensitive to $300 \mathrm{~mm} \mathrm{KCl}$ nor permeable to DAPI (data not shown). Published data indicate myosin II (nmy-2) mutant embryos are also not osmotically sensitive as they do not arrest in water (Guo and Kemphues 1996). It is this unique combination of polarity and osmotic defects that suggested the name of our new polarity mutant pod-1-polarity osmotic defective 1 . 
Rappleye et al.

Table 3. Permeability barrier function of C. elegans eggshell layers

\begin{tabular}{|c|c|c|c|c|c|c|}
\hline \multirow{2}{*}{$\begin{array}{l}\text { Relevant } \\
\text { genotype }\end{array}$} & \multirow[b]{2}{*}{ Treatment $^{\mathrm{a}}$} & \multirow{2}{*}{$\begin{array}{l}\text { Layer(s) } \\
\text { remaining }\end{array}$} & \multicolumn{2}{|c|}{ Osmotic sensitivity $^{\mathrm{b}}$} & \multicolumn{2}{|c|}{$\begin{array}{c}\text { Dye staining of } \\
\text { blastomeres }\end{array}$} \\
\hline & & & $50 \mathrm{~mm} \mathrm{KCl}$ & $250 \mathrm{~mm} \mathrm{KCl}$ & $\overline{\mathrm{DAPI}^{\mathrm{c}}}$ & $\overline{\text { FM4-64 }}{ }^{\mathrm{d}}$ \\
\hline \multirow[t]{4}{*}{ pod-1 $1+1$} & none & all & OK & OK & - & - \\
\hline & bleach & chitinous + lipid-rich & $\mathrm{OK}$ & $\mathrm{OK}$ & - & - \\
\hline & bleach/chitinase & lipid-rich & $\mathrm{OK}$ & OK & - & - \\
\hline & laser pulse & none & swell & shrink & + & + \\
\hline pod-1(ye11) & none & all & swell & shrink & + & + \\
\hline
\end{tabular}

ableach: removal of outer layer; chitinase: removal of middle chitinous layer; laser: perforation of outer, chitinous, and inner lipid layer.

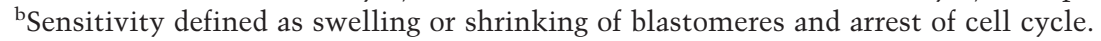

${ }^{\mathrm{c}}$ DAPI staining of blastomere nuclei.

${ }^{\mathrm{d}}$ FM4-64 staining of plasma membranes.

The inner layer of the wild-type eggshell provides a barrier to the external environment

Because the eggshell of other nematodes isolates the embryo from the environment (Wharton 1983), we hypothesized that osmotic sensitivity in the pod-1 mutant results from a defect in the eggshell. If true, then we should be able to phenocopy pod-1(ye11) osmotic sensitivity and dye permeability by removing the eggshell from wild-type embryos.

To our knowledge, the eggshell of C. elegans embryos has not been described previously. The eggshells of parasitic nematodes, on the other hand, have been characterized and are primarily formed of three layers: an outer layer derived from the vitelline membrane of the oocyte, a middle chitinous layer, and an inner lipid-rich layer (Wharton 1980). The inner two layers are both formed by secretion from the egg cytoplasm after fertilization (Wharton 1979). The eggshell itself is a structure distinct from the embryo proper, such that there is a space between the inner lipid-rich layer of the eggshell and the plasma membrane of the embryo.

Each layer was sequentially removed from wild-type C. elegans eggshells and the resulting embryos were tested for osmotic sensitivity and permeability to dye. Wild-type embryos in which the outer two layers have been removed are neither sensitive to salt nor permeable to dyes (Table 3), suggesting that the lipid layer is sufficient to protect embryos. However, perforation of all three eggshell layers of wild-type embryos by a laser phenocopies the osmotic sensitivity and dye permeability of untreated pod-1 mutant embryos (Table 3). These data suggest that the inner layer of the eggshell must be breached to permeabilize the embryo to salt and dyes and therefore, that the inner layer of the eggshell is defective in the pod-1 mutant.

\section{Ultrastructure of the pod-1 mutant reveals formation of extracellular plaque}

To determine whether the eggshell is physically altered in the mutant, we characterized wild-type and mutant eggshells at high resolution using electron microscopy (EM). EM studies of the early embryo are rare and most published procedures for EM of C. elegans embryos require removal of the eggshell (Priess and Hirsh 1986). Therefore, we had to use a different technique. Wild-type and mutant embryos were preserved in the uterus of intact mothers using a high pressure freezer and fixed by freeze substitution.

A three-layered eggshell is seen for wild-type C. elegans (Fig. 5A), similar to that described for parasitic nematodes. Unexpectedly, the eggshell in pod-1(ye11) mutant embryos appears normal and is not obviously compromised by either missing or thinner layers (Fig. 5B). However, large amounts of electron dense material can be seen on the outer surface of mutant embryonic cells, which is not present around wild-type embryonic cells (Fig. 5B). This material appears to be deposited external to the plasma membrane and resembles the inner layer of the eggshell, the layer functionally compromised in the mutant. The present study is apparently the first report in C. elegans of this type of defect.

\section{Discussion}

We have identified a new member of the coronin family of actin-binding proteins that is required for embryonic polarity. The primary sequence of this protein, called POD-1, contains two nearly complete, but degenerate, copies of coronin. To date, no other proteins containing two coronin domains have been reported. However, Northern blot analyses suggest higher molecular weight versions of coronin (analogous to POD-1) may exist in vertebrates as well (Okumura et al. 1998).

Like the previously characterized par genes, loss of pod-1 leads to defects in a-p axis formation. Distinct from par mutants and other developmental mutants, loss of pod-1 also leads to structural abnormalities in embryonic cells. It is these latter defects that set pod-1 apart and that begin to shed light on the actual physical mechanism driving polarity in the early embryo.

pod-1 links developmental polarity to cellular architecture

pod-1 is essential for developmental polarity along the a-p axis of the C. elegans embryo. Loss of pod-1 leads to 


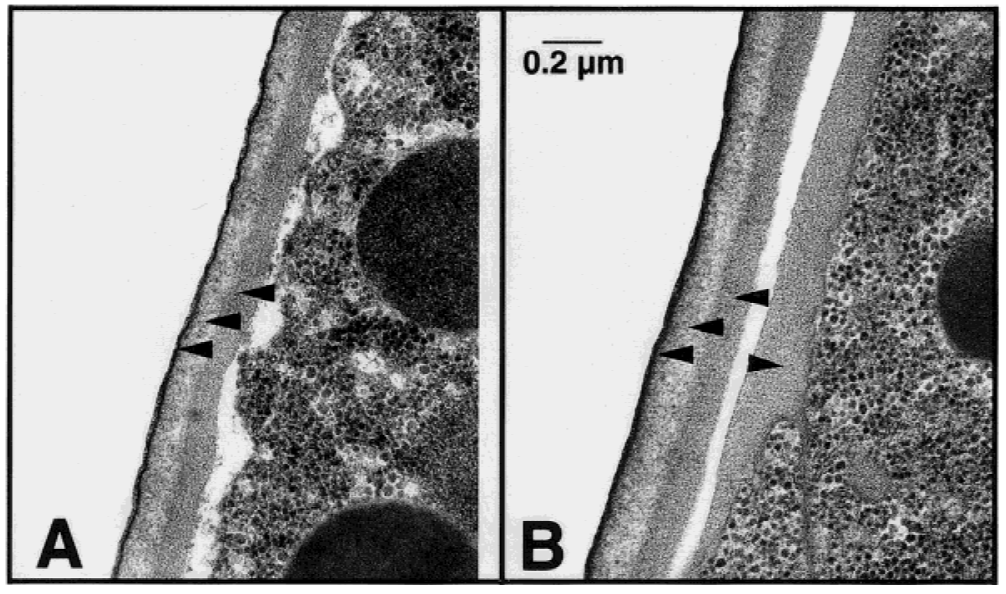

Figure 5. Ultrastructure of wild-type and pod-1 mutant eggshells. In each panel, an embryo (to the right) with its eggshell is shown. (A) Three layers are visible in the wild-type C. elegans eggshells: a thin vitelline layer (black line indicated with lower arrowhead), a chitinous layer (light-staining layer indicated with central arrowhead), and a lipid-rich layer (darker layer indicated by upper arrowhead). (B) All three layers are present and appear normal at this resolution in the pod-1(ye11) eggshell (left pointing arrowheads). However, an extra layer of dark-staining material is evident on the outside of the pod-1 mutant embryos (right pointing arrowhead) that is not evident in wild type.

loss of $\mathrm{AB} / \mathrm{P}_{1}$ size asymmetry in the first cleavage, loss of orthogonal division planes in the second cleavages, and loss of polarized flows during the first cell cycle. Polarization of a cytoplasmic marker ( $\mathrm{P}$ granules to the posterior) and cortical markers (PAR-3 to the anterior and PAR-1 to the posterior) are compromised. The penetrance of these phenotypes varies from $~ 50 \%$ to $100 \%$ suggesting that not all aspects of polarity are equally affected and that aspects of polarization can sometimes occur in the absence of POD-1. Nonetheless, POD-1 clearly plays an important role in the establishment of a-p polarity.

Loss of pod-1 also gives rise to specific defects in the architecture of the embryo. These defects occur intracellularly, intercellularly, and extracellularly. They include formation of large membrane-bound compartments of apparent endocytic origin, extension of granule-free hyaline zones, loss of membrane integrity between sister cells, abnormal permeability of the eggshell, and the formation of plaque material on the outside of embryonic cells. These defects share a striking resemblance to phenotypes seen in the Dictyostelium coronin mutant, namely defects in endocytosis/phagocytosis, formation of hyaline zones, and defects in cell division (De Hostos et al. 1993; Gerisch et al. 1995; Maniak et al. 1995; Hacker et al. 1997). Although there are multiple physical defects associated with the pod-1 mutant, pod-1 is not a general regulator of actin architecture as indicated by the fact that it has no essential zygotic role nor does its loss lead to gross alterations in the distribution of cellular actin.

pod-1 is only the second cytoskeletal-associated protein shown to be important for a-p polarity. RNAi studies of nonmuscle myosin II (nmy-2) have shown that it too is required for embryonic polarity (Guo and Kemphues 1996). However, pod-1 differs from nmy-2 in several respects. POD-1 protein is localized asymmetrically in the cortex of the one-cell embryo, whereas NMY-2 protein is uniformly localized in the cortex. The simple interpretation is that POD-1 participates in a polarized process, hence playing a direct role in asymmetry, whereas NMY-2 participates in a nonpolarized process that is required indirectly for asymmetry. Also, NMY-2 has a more limited effect on the structure of embryonic cells. The only structural defect associated with NMY-2 is in cytokinesis.

The study of pod-1 spans two important biological fields-embryonic development and the cytoskeletonand appears to link developmental polarity with cell structure in a way not previously characterized in $C$. elegans. Mutations like ye11 have been largely ignored due to the difficulty in analyzing mutants with structural and developmental defects versus mutants, like the par's, which affect only developmental processes.

\section{POD-1 and the par protein pathway}

Our results suggest that POD-1 functions at a fairly early step in the generation of a-p polarity. Our data indicate that POD-1 acts upstream of PAR-1 in the one-cell embryo as POD-1 is required for PAR-1 asymmetric localization, but PAR-1 is not required for POD-1 asymmetric localization. In contrast, POD-1 and PAR-3 are mutually dependent for their asymmetric localizations, suggesting that POD-1 and PAR-3 act at a similar part of the pathway for generating one-cell asymmetry.

Recently, conservation of action has been noted between some of the genes in the determination of C. elegans a-p polarity and human epithelial cell polarity. In particular, mammalian homologs of PAR-3 and PAR-1 have been implicated in establishing the polarity of epithelial cells, with the homologs being localized to the tight junction and basolateral domain respectively (Boehm et al. 1997; Izumi et al. 1998). In addition, atypical protein kinase C (PKC-3), which may be important for maintaining polarity in epithelial cells (Izumi et al. 19981, associates with PAR-3, is localized to the anterior cortex of the one-cell embryo, and is also required for a-p polarity in C. elegans (Tabuse et al. 1998). Interestingly, it has been suggested that protein kinase C phosphorylates directly or indirectly coronin in rabbit epithelial cells (Parente et al. 1999). Thus, there may be a conserved relationship in worms and vertebrates between protein kinase $\mathrm{C}$ and coronin. These observations sug- 
gest that a coronin-like gene may play a role in epithelial polarity as well.

\section{Models for POD-1 function and embryonic polarity}

What is the function of pod-1 in embryonic cells and how does its function relate to the establishment of a-p polarity? One model is that POD-1 regulates cellular architecture and, independently, regulates polarity, perhaps by recruiting polarity proteins to the anterior cortex. Alternatively and more simply, the effects of POD-1 on cell structure might be directly responsible for $a-p$ polarity. One version of this model is that POD-1 binds asymmetrically and modulates the organization of F-actin in the cell (e.g., by cross-linking) and that this organization of actin plays an important role in cell polarity. Consistent with POD-1 playing a role in actin organization, it is hypothesized that coronin reorganizes actin in dynamic regions of the Dictyostelium cortex (De Hostos et al. 1993; Gerisch et al. 1995) and yeast coronin crosslinks actin filaments (Goode et al. 1999). However, arguing against such a role, loss of coronin/pod-1 does not perturb the overt organization of actin in any organism where it has been mutated (De Hostos et al. 1993; HeilChapdelaine et al. 1998; Goode et al. 1999; this study).

Careful assessment of the structural phenotypes associated with loss of pod-1 and the fact that coronin plays an important role in endocytosis compel us to consider an alternative model. Namely, that the dominant function of pod-1 is in membrane trafficking and that, as in epithelial cells (Drubin and Nelson 1996) membrane trafficking is playing a major role in polarizing the $C$. elegans embryo.

Many of the architectural defects seen in the pod-1 mutant can be best explained by problems with membrane trafficking in the cell. The large endocytic compartments formed in the mutant are reminiscent of swollen endosomes formed in other cell types either by the premature fusion of newly endocytosed vesicles or by problems in exiting from late endosomes/the multivesicular body in the endocytic pathway (Murphy et al. 1996; Reaves et al. 1996; Fernandez-Borja et al. 1999). The permeability of pod-1 mutant embryos to salt and dyes appears to be caused by defects in the eggshell, a structure secreted from the embryo after fertilization. EM studies of the mutant reveal accumulation on embryonic cells of material that resembles the inner layer of the eggshell. This accumulation might represent a failure to endocytose material normally taken into embryonic cells (e.g., extra eggshell material secreted but not needed) or an exocytic defect whereby too much eggshell material is secreted or is secreted too slowly, such that some remains attached to the embryo after the eggshell forms.

One simple mechanism to explain how embryonic polarity is linked to membrane trafficking involves the flows that occur early in the first cell cycle. These flows, generated by the sperm, have been suggested to play an important role in a-p axis formation (Hird and White 1993; Goldstein and Hird 1996). At the very posterior of the embryo, these flows move from posterior to anterior along the cortex while in the anterior of the embryo these flows move from anterior to posterior in the cytoplasm. In the pod-1 mutant, these flows are largely lacking and cytoplasmic $P$ granules, which may be carried by these flows, are inhibited in their movement to the posterior. We hypothesize that membrane trafficking drives these flows. For example, a balance between exocytosis at the posterior end of the embryo and endocytosis at the anterior end of the embryo, where pod-1 is enriched, would set up such a flow. In the absence of pod-1 and pod-1-mediated trafficking, such a flow, and hence a-p polarity, would be compromised.

Studies of embryonic polarity in the past have largely relied on genetic screens and selections for mutations that strictly affect the developmental process. As such, an impressive list of genes has been identified that are required for establishing asymmetry, but we understand relatively little as to the cellular processes involved. Genes like pod-1, because of their more complicated phenotypes, have been relatively understudied. Yet, ultimately, these genes are likely to provide critical insights into the physical mechanisms underlying polarity establishment.

\section{Materials and methods}

Strains and genetics

Culture and manipulation of C. elegans strains were done using standard techniques (Brenner 1974). The following mutant alleles were used: LGI emb-14(g43), emb-20(g27), par-6(zu222) unc-101(m1)/hln1; LGIII unc-32(e189), plg-1(e2001), dpy-18(e364) unc-64(e246), unc-32(e189) par-3(it71)/qC1, unc-32(e189) pod1(ye11)/qC1, unc-32(e189) tDf8/(qC1), par-2(lw32) unc45(e286ts)/ sC1, unc-32(e189) ooc-4(e2078)/eDf2 eT1(III;V); LGIV par1(b274) rol-4(sc8)/nT1(IV;V), dpy-20(e1282) par-5(it55)/DnT1; LGV par-4(it47 ts). The alleles of par-1, par-2, par-3, and par-4 used are likely null or strong reduction-of-function alleles (Kirby et al. 1990; Levitan et al. 1994; Cheng et al. 1995).

For the zygotic test of pod-1 function, the total progeny produced from hermaphrodites of the genotype unc-32(e189) pod1(ye11)/qC1 were counted; 155 of 607 were Unc Pod and developed into adults. To test the maternal requirement, pod-1(+); plg-1(e2001) males were mated to unc-32(e189) pod-1(ye11) hermaphrodites (the plg-1(e2001) mutation allows verification of mating success; Hodgkin and Doniach 1997).

\section{Cloning and molecular analysis of the pod-1 locus}

CABP11 antibodies were used to screen a $\lambda$ gt1 1 embryo library. A clone was isolated that contained the $3^{\prime}$ end of the pod-1 transcript. This clone was shown to encode the CABP11 protein as antibodies made against two nonoverlapping polypeptides encoded by this clone behaved like CABP11 antibody on fixed embryos and Western blots (Fig. 3B; data not shown). The 5' end was cloned by PCR of reverse transcribed total RNA using oligonucleotides specific for the lambda clone and the SL1 splice leader (Zorio et al. 1994). The predicted protein sequence of our complete cDNA is identical to that predicted by the genome project. The complete cDNA and predicted protein sequences have been deposited in Genbank (accession no. AF129126). 


\section{RNAi}

RNAs were used to deplete maternal POD-1 protein from embryos as described (Fire et al. 1998). Templates for RNA synthesis were prepared from pod-1 partial and full-length cDNAs cloned into pBluescript (Stratagene) using the T3 and T7 sites of the vector or, for coronin, by PCR of reverse-transcribed RNA using coronin-specific oligonucleotides with attached T3 and T7 sites (available upon request). RNAs were prepared using RNA synthesis kits (AMBION) and microinjected $(1 \mathrm{mg} / \mathrm{ml})$ into both arms of the gonad. Coronin RNAs were coinjected with unc-22 RNAs (Fire et al. 1998) to verify that the injection had worked (all hatched animals exhibited the Unc-22 phenotype). With pod-1 RNAs, fully penetrant embryo lethality is reached by $16-20 \mathrm{hr}$ after injection, and depletion of POD-1 protein was confirmed by immunofluorescence.

\section{Isolation and characterization of pod-1 deletion allele}

The pod-1 deletion allele ye11 was isolated by a PCR-based, $\mathrm{F}_{1}$ screen of 575,000 EMS-mutagenized worms using an established protocol (http://snmc01.omrf.uokhsc.edu/revgen/RevGen.html). Screening for pod-1 deletions was done using pod1-specific oligonucleotides $\left(11 \mathrm{~F}_{2}\right.$ : GCACTGGTTTCACTACGGTAAGAAGC; 2R4: TCGACAGCCATCACGTTAC). The deletion was outcrossed 10 times and linked to the unc-32(e189) allele by mating to unc-32(e189) $t D f 8 / q C 1$ and isolating Unc $\mathrm{F}_{2}$ progeny. The pod-1(ye11) allele was then placed over the chromosome III balancer $q C 1$, which balances pod-1 (unpublished data).

For deficiency testing, the pod-1(ye11) chromosome was first marked with the $d p y-18$ mutation by isolating Dpy non-Unc progeny from $d p y-18(e 364)$ unc-64(e2078)/pod-1(ye11) hermaphrodites. pod-1(ye11)/eDf2 hermaphrodites were obtained by mating $d p y-18(e 364)$ pod-1(ye11)/eT1 males into eDf2 heterozygotes and picking Dpy F1 progeny (eDf2 spans both $d p y-18$ and pod-1).

\section{Microscopy of embryos}

For observing live embryos, embryos were dissected from gravid hermaphrodites in isotonic medium [150 $\mathrm{mm} \mathrm{KCl}, 5 \mathrm{~mm}$ HEPES (pH 7.5)] or embryonic blastomere growth medium (Shelton and Bowerman 1996) and mounted on slides. Coverslips were supported at the edges by petroleum jelly to prevent pressure being applied to the embryos. Embryos were observed from pronuclear migration through the 6- to 7-cell stage using DIC optics and recorded using a time-lapse VCR or CCD camera. Observations were done at $16-18^{\circ} \mathrm{C}$.

The symmetry of the first cleavage was determined by measuring [using National Institutes of Health (NIH) Image v1.61] the cross sectional area of the anterior and posterior blastomeres at the completion of the first cytokinesis. Cleavage was judged symmetric if the relative area of the anterior blastomere was $<53 \%$ [wild-type area of $\mathrm{AB}, 56.7 \pm 1.4 \%(n=5)$ ], a conservative upper limit consistent with that reported for par mutant embryos (Kemphues et al. 1988). Using this value, embryos fell into two classes: symmetric and asymmetric with average $\mathrm{AB}$ sizes of $51 \pm 1 \%$ and $57 \pm 3 \%$, respectively.

Osmotic sensitivity of embryos was determined by mounting embryos in $5 \mathrm{~mm}$ HEPES-buffered media (pH 7.5) with $50 \mathrm{~mm}$ increments of $\mathrm{KCl}$. Swelling of blastomeres indicated hypotonic conditions and shrinking of blastomeres was scored as hypertonic. Dye staining of live embryos was done by inclusion of 10 ng/ul DAPI or $32 \mu \mathrm{M}$ FM 4-64 (Molecular Probes) in the medium. For comparison to other osmotic mutants, emb-14(g43) and $e m b-20(g 27)$ (Cassada et al. 1981) were grown at permissive temperature and shifted as fourth larval stages to nonpermissive temperature overnight. The shrinking and swelling of emb-14 and $e m b-20$ embryos in different salt concentrations and permeability to FM 4-64 and DAPI were tested. Both mutants behaved the same as pod-1. Eleven emb-14 and $13 \mathrm{emb}-20$ mutant embryos that progressed from pronuclear migration of the onecell stage to the two-cell stage in EBGM at $25^{\circ} \mathrm{C}$ were lineaged and the relative sizes of the blastomeres measured as above.

\section{Permeabilization of pod-1(+) eggshells}

The outer eggshell layer was removed from wild-type embryos by treatment with $150 \mathrm{~mm} \mathrm{NaOCl}$ for 3-5 min followed by one to two washes in excess fetal bovine serum to quench the hypochlorite. Removal of the chitinous layer from hypochloritetreated embryos was accomplished by washing embryos twice in $150 \mathrm{~mm} \mathrm{KCl}$ followed by $5 \mathrm{~min}$ in chitinase $[20 \mathrm{mg} / \mathrm{ml}$ chitinase, $130 \mathrm{~mm} \mathrm{KCl}, 2.5 \mathrm{~mm} \mathrm{MgCl}_{2}, 2.5 \mathrm{~mm} \mathrm{CaCl}_{2}, 5 \mathrm{~mm}$ HEPES (pH 7.5)]. Successful removal of both layers of the outer eggshell was judged by the absence of a visible eggshell at 1000× magnification. Permeablization of all three layers of the eggshell was accomplished by puncturing the eggshell with a laser pulse (Schierenberg and Junkersdorf 1992) or by isolation of individual blastomeres (Shelton and Bowerman 1996).

\section{Antibodies and immunofluorescence of embryos}

Polyclonal antibodies recognizing POD-1 were generated by immunization of rabbits (Berkeley Antibody Co., Richmond, CA) with POD-1 fragments 11-1 and 11-9 (corresponding to residues 452-592 and 933-1055, respectively) fused to GST. The 11-1 antibody was affinity purified by depletion of GST antibodies then by purification over a column of 11-1 protein. 11-9 antibody was affinity purified over a column of 11-9 protein fused to maltose-binding protein.

Wild-type embryos were fixed and costained in solution with POD-1 and actin antibodies and DAPI as described (Aroian et al. 1997), except sucrose was used at $8 \%$. The new POD-1 antibodies (mostly 11-1) were used at 1:1000-1:2000. Actin staining is used to control for preservation of the cortex, and POD-1 staining was judged relative to actin. For staining of par mutants, where it is more difficult to obtain enough embryos using insolution techniques, we used standard freeze fracture (see below) and fixation in methanol for $4 \mathrm{~min}$. This procedure gives less robust and less consistent actin staining and, in our hands, is inferior to in-solution fixation. Using freeze fracture, 66/73 wild-type embryos between pronuclear meeting and metaphase showed some enrichment of POD-1 in the anterior cortex and cytoplasm. Although it is not possible to determine unambiguously whether the anterior-most cortex of $\mathrm{P}_{1}$ contains POD- 1 as it abuts the posterior cortex of $\mathrm{AB}$, we believe it does (see Aroian et al. 1997).

Fixation of pod-1 mutant embryos and staining with PAR-1, PAR-3, and germ-line granule antibodies (K76) were done according to published protocols (Etemad-Moghadam et al. 1995; Guo and Kemphues 1995), except the embryos were released in isotonic buffer. Staining with FITC-labeled tubulin antibody (DM1a; Sigma) was included to aid in unambiguous determination of cell cycle state. For POD-1 and actin costainings, embryos were fixed in $4 \%$ formaldehyde, $75 \% \mathrm{MeOH}, 3 \%$ sucrose, $1 \times$ cytoskeletal buffer for $15 \mathrm{~min}$ followed by $5 \mathrm{~min}$ of fixation in $100 \% \mathrm{MeOH}$.

Immunofluorescence of embryos was observed with a deconvolution system (DeltaVision 2.10, Applied Precision) using an Olympus IX-70 inverted microscope (60× 1.40 NA objective) 
and a Micromax camera (Princeton Instruments, Inc.). Image stacks were collected with 0.1 - to $0.7-\mu \mathrm{m}$ sections and deconvolution performed according to the Agard \& Sedat inverse matrix algorithm.

\section{$E M$}

Adult worms containing embryos were prepared for EM by high pressure freezing (HPF) followed by freeze-substitution (Dernburg et al. 1998; McDonald 1999|. For HPF, 20-30 worms were mixed with a paste made from dry baker's yeast and $10 \%$ methanol in distilled water to facilitate loading into a $100-\mu \mathrm{m}$ deep specimen carrier. Worms were cryofixed in a Bal-Tec HPM 010 high pressure freezer (Technotrade International, Manchester, $\mathrm{NH}$ ), freeze-substituted in $2 \%$ osmium tetroxide plus $0.1 \%$ uranyl acetate in acetone for 2 days at $-78^{\circ} \mathrm{C}$, then warmed to $-20^{\circ} \mathrm{C}$ over a $12-\mathrm{hr}$ period. After $12 \mathrm{hr}$ at $-20^{\circ} \mathrm{C}$ the samples were warmed to room temperature over a 6-hr period, rinsed five times in pure acetone, infiltrated with Epon-Araldite resin, and then flat embedded (Howard and O'Donnell 1987). Samples were remounted and $60-\mathrm{nm}$ longitudinal sections cut on a Reichert Ultracut E ultramicrotome. These were picked up on Formvar-coated slots, post-stained with uranyl acetate and lead citrate, and viewed in a JEOL 100CX EM operating at $80 \mathrm{kV}$.

\section{Acknowledgments}

We thank Bruce Alberts in whose laboratory this work was begun. We are grateful to Ken Kemphues for PAR-1 and PAR-3 antibodies and for par strains; Peter Okkema for his expression library; Vivek Malhotra, Ethan Bier, Scott Emr, Rick Firtel, Velia Fowler, Jim Posakony, Mani Ramaswami, Steve Wasserman, and members of the Aroian laboratory for discussions and critical readings of this manuscript; Theresa Stiernagle at the $C$. elegans Genetics Center (funded by the NIH National Center for Research Resources) for providing strains; Lesilee Rose for personal communication; Mike Nonet for the $d p y-18$ unc-64 strain; Craig Hunter, Chris Shelton, Azmi Nassar, and Lisa Marroquin for technical assistance; Negin Iranfar for sequencing; and Bill Schafer for use of his laser. This work was supported by National Science Foundation (NSF) Research Grant IBN-9808911, a James A. Shannon Director's Award from the $\mathrm{NIH}$, an American Cancer Society Institutional Award, and Hellman Faculty Fellowship to R.V.A., and by a Howard Hughes Predoctoral Fellowship to C.A.R.

The publication costs of this article were defrayed in part by payment of page charges. This article must therefore be hereby marked "advertisement" in accordance with 18 USC section 1734 solely to indicate this fact.

\section{References}

Aroian, R.V., C. Field, G. Pruliere, C. Kenyon, and B.M. Alberts. 1997. Isolation of actin-associated proteins from Caenorhabditis elegans oocytes and their localization in the early embryo. EMBO J. 16: 1541-1549.

Boehm, H., V. Brinkmann, M. Drab, A. Henske, and T.V. Kurzchalia. 1997. Mammalian homologues of C. elegans PAR-1 are asymmetrically localized in epithelial cells and may influence their polarity. Curr. Biol. 7: 603-606.

Bowerman, B. 1998. Maternal control of pattern formation in early Caenorhabditis elegans embryos. In Current Topics in Developmental Biology (ed. R.A. Pedersen and G.P. Schatten), pp. 73-117. Academic Press, Inc., San Diego, CA.

Boyd, L., S. Guo, D. Levitan, D.T. Stinchcomb, and K.J. Kem- phues. 1996. PAR-2 is asymmetrically distributed and promotes association of $\mathrm{P}$ granules and PAR-1 with the cortex in C. elegans embryos. Development 122: 3075-3084.

Brenner, S. 1974. The genetics of Caenorhabditis elegans. Genetics 77: 71-94.

Broadus, J. and C.Q. Doe. 1997. Extrinsic cues, intrinsic cues and microfilaments regulate asymmetric protein localization in Drosophila neuroblasts. Curr. Biol. 7: 827-835.

Cassada, R., E. Isnenghi, M. Culotti, and G. von Ehrenstein. 1981. Genetic analysis of temperature-sensitive embryogenesis mutants in Caenorhabditis elegans. Dev. Biol. 84: 193205.

Cheng, N.N., C.M. Kirby, and K.J. Kemphues. 1995. Control of cleavage spindle orientation in Caenorhabditis elegans: The role of the genes par-2 and par-3. Genetics 139: 549-559.

David, V., E. Gouin, M. Van Troys, A. Grogan, A.W. Segal, C. Ampe, and P. Cossart. 1998. Identification of cofilin, coronin, Rac and capZ in actin tails using a Listeria affinity approach. J. Cell Sci. 111: 2877-2884.

De Hostos, E.L., C. Rehfuess, B. Bradtke, D.R. Waddell, R. Albrecht, J. Murphy, and G. Gerisch. 1993. Dictyostelium mutants lacking the cytoskeletal protein coronin are defective in cytokinesis and cell motility. J. Cell Biol. 120: 163-173.

Denich, K.T.R., E. Schierenberg, E. Isnenghi, and R. Cassada. 1984. Cell-lineage and developmental defects of temperature-sensitive embryonic arrest mutants of the nematode Caenorhabditis elegans. Roux's Arch. Dev. Biol. 193: 164 179.

Dernburg, A.F., K. McDonald, G. Moulder, R. Barstead, M. Dresser, and A.M. Villeneuve. 1998. Meiotic recombination in C. elegans initiates by a conserved mechanism and is dispensable for homologous chromosome synapsis. Cell 94: 387-398.

Drubin, D.G. and W.J. Nelson. 1996. Origins of cell polarity. Cell 84: 335-344.

Etemad-Moghadam, B., S. Guo, and K.J. Kemphues. 1995. Asymmetrically distributed PAR-3 protein contributes to cell polarity and spindle alignment in early C. elegans embryos. Cell 83: 743-752.

Fernandez-Borja, M., R. Wobbolts, J. Calafat, H. Janssen, N. Divecha, S. Dusselijee, and J. Neefjes. 1999. Multivesicular body morphogenesis requires phosphatidylinositol 3-kinase activity. Curr. Biol. 9: 55-58.

Fire, A., S. Xu, M.K. Montgomery, S.A. Kostas, S.E. Driver, and C.C. Mello. 1998. Potent and specific genetic interference by double-stranded RNA in Caenorhabditis elegans. Nature 391: 806-811.

Fowler, J.E. and R.S. Quatrano. 1995. Cell polarity, asymmetric division, and cell fate determination in brown algal zygotes. Sem. Dev. Biol. 6: 347-358.

Gerisch, G., R. Albrecht, C. Heizer, S. Hodgkinson, and M. Maniak. 1995. Chemoattractant-controlled accumulation of coronin at the leading edge of Dictyostelium cells monitored using a green fluorescent protein-coronin fusion protein. Curr. Biol. 5: 1280-1285.

Goldstein, B. and S.N. Hird. 1996. Specification of the anteroposterior axis in Caenorhabditis elegans. Development 122: $1467-1474$.

Goode, B.L., J.J. Wong, A.-C. Butty, M. Peter, A.L. McCormack, J.R. Yates, D.G. Drubin, and G. Barnes. 1999. Coronin promotes the rapid assembly and cross-linking of actin filaments and may link the actin and microtubule cytoskeletons in yeast. J. Cell Biol. 144: 83-98.

Grogan, A., E. Reeves, N. Keep, F. Wientjes, N.F. Totty, A.L. Burlingame, J.J. Hsuan, and A.W. Segal. 1997. Cytosolic phox proteins interact with and regulate the assembly of 
coronin in neutrophils. J. Cell Sci. 110: 3071-3081.

Gueth-Hallonet, C. and B. Maro. 1992. Cell polarity and cell diversification during early mouse embryogenesis. Trends Genet. 8: 274-279.

Guo, S. and K.J. Kemphues. 1995. par-1, a gene required for establishing polarity in C. elegans embryos, encodes a putative Ser-Thr kinase that is asymmetrically distributed. Cell 81: 611-620.

1996. A non-muscle myosin required for embryonic polarity in Caenorhabditis elegans. Nature 382: 455-458.

Hacker, U., R. Albrecht, and M. Maniak. 1997. Fluid-phase uptake by macropinocytosis in Dictyostelium. I. Cell Sci. 110: 105-112.

Heil-Chapdelaine, R.A., N.K. Tran, and J.A. Cooper. 1998. The role of Saccharomyces cerevisiae coronin in the actin and microtubule cytoskeletons. Curr. Biol. 8: 1281-1284.

Hill, D.P. and S. Strome. 1988. An analysis of the role of microfilaments in the establishment and maintenance of asymmetry in Caenorhabditis elegans zygotes. Dev. Biol. 125: $75-84$.

Hird, S.N. and J.G. White. 1993. Cortical and cytoplasmic flow polarity in early embryonic cells of Caenorhabditis elegans. J. Cell Biol. 121: 1343-1355.

Hird, S.N., J.E. Paulsen, and S. Strome. 1996. Segregation of germ granules in living Caenorhabditis elegans embryos: Cell-type-specific mechanisms for cytoplasmic localisation. Development 122: 1303-1312.

Hodgkin, J. and T. Doniach. 1997. Natural variation and copulatory plug formation in Caenorhabditis elegans. Genetics 146: $149-164$.

Howard, R.J. and K.L. O'Donnell. 1987. Freeze substitution of fungi for cytological analysis. Exper. Mycol. 11: 250-269.

Izumi, Y., T. Hirose, Y. Tamai, S.-I. Hirai, Y. Nagashima, T. Fujimoto, Y. Tabuse, K.J. Kemphues, and S. Ohno. 1998. An atypical PKC directly associates and colocalizes at the epithelial tight junction with ASIP, a mammalian homologue of Caenorhabditis elegans polarity protein PAR-3. J. Cell Biol. 143: 95-106.

Kemphues, K.J., J.R. Priess, D.G. Morton, and N.S. Cheng. 1988. Identification of genes required for cytoplasmic localization in early C. elegans embryos. Cell 52: 311-320.

Kirby, C., M. Kusch, and K. Kemphues. 1990. Mutations in the par genes of Caenorhabditis elegans affect cytoplasmic reorganization during the first cell cycle. Dev. Biol. 142: 203215.

Levitan, D.J., L. Boyd, C.C. Mello, K.J. Kemphues, and D.T. Stinchcomb. 1994. par-2, a gene required for blastomere asymmetry in Caenorhabditis elegans, encodes zinc-finger and ATP-binding motifs. Proc. Natl. Acad. Sci. 91: 61086112.

Maniak, M., R. Rauchenberger, R. Albrecht, J. Murphy, and G. Gerisch. 1995. Coronin involved in phagocytosis: Dynamics of particle-induced relocalization visualized by a green fluorescent protein tag. Cell 83: 915-924.

McDonald, K.L. 1999. High pressure freezing for preservation of high resolution fine structure and antigenicity for immunolabeling. Methods Mol. Biol. 117: 77-97.

Murphy, C., R. Saffrich, M. Grummt, H. Gournier, V. Rybin, M. Rubino, P. Auvinen, A. Luetcke, R.G. Parton, and M. Zerial. 1996. Endosome dynamics regulated by a Rho protein. $\mathrm{Na}$ ture 384: 427-432.

Okumura, M., C. Kung, S. Wong, M. Rodgers, and M.L. Thomas. 1998. Definition of family of coronin-related proteins conserved between humans and mice: Close genetic linkage between coronin-2 and CD45-associated protein. DNA Cell Biol. 17: 779-787.
Parente, J.A., X. Chen, C. Zhou, A.C. Petropoulos, and C.S. Chew. 1999. Isolation, cloning, and characterization of a new mammalian coronin family member, coronin $_{\mathrm{se}}$, which is regulated within the protein kinase $\mathrm{C}$ signaling pathway. J. Biol. Chem. 274: 3017-3025.

Penninger, J.M. and G.R. Crabtree. 1999. The actin cytoskeleton and lymphocyte activation. Cell 96: 9-12.

Priess, J.R. and D.I. Hirsh. 1986. Caenorhabditis elegans morphogenesis: The role of the cytoskeleton in elongation of the embryo. Dev. Biol. 117: 156-173.

Rauchenberger, R., U. Hacker, J. Murphy, J. Niewoehner, and M. Maniak. 1997. Coronin and vacuolin identify consecutive stages of a late, actin-coated endocytic compartment in Dictyostelium. Curr. Biol. 7: 215-218.

Reaves, B.J., N.A. Bright, B.M. Mullock, and J.P. Luzio. 1996. The effect of wortmannin on the localisation of lysosomal type I integral membrane glycoproteins suggests a role for phosphoinositide 3-kinase activity in regulating membrane traffic late in the endocytic pathway. J. Cell Sci. 109: 749762.

Rocheleau, C.E., W.D. Downs, R. Lin, C. Wittmann, Y. Bei, Y. Cha, M. Ali, J.R. Priess, and C.C. Mello. 1997. Wnt signaling and an APC-related gene specify endoderm in early C. elegans embryos. Cell 90: 707-716.

Schierenberg, E. and B. Junkersdorf. 1992. The role of eggshell and underlying vitelline membrane for normal pattern formation in the early C. elegans embryo. Roux's Arch. Dev. Biol. 202: 10-16.

Shelton, C.A. and B. Bowerman. 1996. Time-dependent responses to glp-1-mediated inductions in early C. elegans embryos. Development 122: 2043-2050.

Swan, K.A., A.F. Severson, J.C. Carter, P.R. Martin, H. Schnabel, R. Schnabel, and B. Bowerman. 1998. cyk-1: A C. elegans FH gene required for a late step in embryonic cytokinesis. J. Cell Sci. 11: 2017-2027.

Tabuse, Y., Y. Izumi, F. Piano, K.J. Kemphues, J. Miwa, and S. Ohno. 1998. Atypical protein kinase C cooperates with PAR-3 to establish embryonic polarity in Caenorhabditis elegans. Development 125: 3607-3614.

Takizawa, P.A., A. Sil, J.R. Swedlow, I. Herskowitz, and R.D. Vale. 1997. Actin-dependent localization of an RNA encoding a cell-fate determinant in yeast. Nature 389: 90-93.

Vida, T.A. and S.D. Emr. 1995. A new vital stain for visualizing vacuolar membrane dynamics and endocytosis in yeast. $I$. Cell Biol. 128: 779-792.

Wharton, D. 1980. Nematode egg-shells. Parasitology 81: 447463.

Wharton, D.A. 1979. Oogenesis and egg-shell formation in Aspiculuris tetraptera Schulz (Nematoda: Oxyuroidea). Parasitology 78: 131-143.

- 1983. The production and functional morphology of helminth egg-shells. Parasitology 86: 85-97.

Winckler, B., P. Forscher, and I. Mellman. 1999. A diffusion barrier maintains distribution of membrane proteins in polarized neurons. Nature 397: 698-701.

Zorio, D.A., N.N. Cheng, T. Blumenthal, and J. Spieth. 1994. Operons as a common form of chromosomal organization in C. elegans [see comments]. Nature 372: 270-272. 


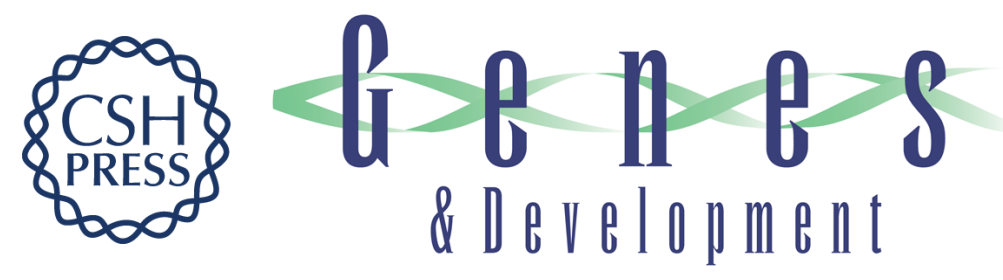

\section{The coronin-like protein POD-1 is required for anterior-posterior axis formation and cellular architecture in the nematode Caenorhabditis elegans}

Chad A. Rappleye, Alexander R. Paredez, Carol W. Smith, et al.

Genes Dev. 1999, 13:

References This article cites 52 articles, 19 of which can be accessed free at:

http://genesdev.cshlp.org/content/13/21/2838.full.html\#ref-list-1

License

Email Alerting Receive free email alerts when new articles cite this article - sign up in the box at the top Service right corner of the article or click here.

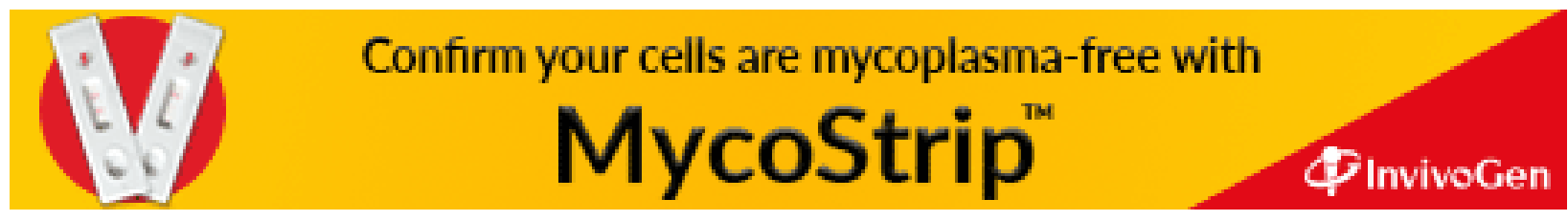

